\title{
Conundrums of Government: The Outer Limits of Policy Analysis
}

\author{
Ira Sharkansky \\ Professor of Political Science and Public Administration \\ The Hebrew University of Jerusalem
}

\begin{abstract}
Conundrums have no solution. They are ambiguous, multifaceted, and do not lend themselves to quantilative assessment of their components. They produce shorlfalls in policy accomplishments, and frustration among those charged with policymaking. To recognize the generality of conundrums is to prepare to cope with them. The use of the term coping is significant. The term implies something less than finding solutions to problems. Words like adaptation, managing, and dealing with appear in discussions of coping. It is inherent in the nature of coping strategies that they provide only partial and imperfect solutions to problems that are insoluble. Some of the strategies outlined here may actually make some aspects of a conundrum worse, even while they offer solutions to other aspects. The strategies include redefining a problem to put the focus on its soluble elements; entrepreneurialism; deviousness; breaking the rules; indirection; reform; and redundancy. In the final analysis, the quality of policy analysis and governmental performance is limited by conundrums. No matter how good the elected officials and civil servants, conundrums keep policymakers from knowing exactly what they are doing, force a certain amount of conjecture into their decisions, and encourage posturing and exaggeration as techniques of persuasion.
\end{abstract}

In so far as politics deals with the competing demands of individuals and groups, the destinies of conundrums ${ }^{1 /}$ and politics seem bound to meet. Conundrum is an old word, whose rich meanings and implications are themselves problematic. However, the term deserves a place in the literature of policy analysis. The common focus of its various meanings is on problems that elude solution.

V.O. Key introduced a conundrum four and one-half decades ago in a classic article on budgeting:

On what basis shall it be decided to allocate $\mathrm{x}$ dollars to activity $\mathrm{A}$ instead of activity $B ?^{22}$

1) Dictionaries agree that the origin of the word is not Latin. As a result, the plural will use the English form with an "s", rather than the Latinized "conundra".

2) V.O. Key, Jr., "The Lack of a Budgetary Theory," American Political Science Review, Vol. 34 (December, 1940), pp. 1137-44. 
Although budgeting has become one of the most thoroughly documented fields of political science, Key's question still waits an answer. Indeed, there is a more general coundrum, which subsumes Key's complaint:

How to determine the impact of $\mathrm{x}$ policy ingredient (which may be an issue of budget, personnel, organizational design, or program detail) on the results of public policy when the number of potential influences on the results of policy are so great as to foil any attempt to define the impact of any particular influence?

Another kind of conundrum develops within a particular setting. It reflects the confluence of elements which both challenge the government, and question the merits of solutions that are proposed.

The triple-digit inflation that dominated Israel's policy scene from 1980 through 1985 illustrated a conundrum that was specific to time and place. The inflation was accompanied by sizable government expenditures and budget deficits, a lack of economic growth, increased foreign debt, a chronic balance of payments deficit, indexation that linked incomes to increases in the consumer price index, and a political setting that required several competitive parties to accomodate to one another in a coalition government. The multiple elements that seemed linked together, and ambiguous notions of cause and effect made this tangle of problems into a conundrum. The questions that seemed unanswerable were which of these holds the key to inflation? and Which can be altered in a way to end inflation? Even now when the inflation has dropped to 24 percent for the year ending July, 1986, it is not clear as to which government actions contributed how much to the decline, in the context of several international factors that also worked to the benefit of Israel's economy.

Still without solution is the conundrum of Iarael's security and foreign relations, that has bedevilled the country since it achieved independence 38 years ago: how to find a path to peaceful relations with its neighbors when various Arab countries or organizations insist on extreme positions of not recognizing lsrael's legitimate right to exist?

The Oxford English Dictionary indicates that "conundrum" appeared as early as 1645, perhaps as part of a university joke. ${ }^{3 \prime}$ Such a beginning justifies academic concern for conundrums. It also cautions those who examine conundrums to arm themselves with skeptism and irreverence.

Webster's New Collegiate Dictionary indicates that a conundrum is "a question or a prob-

3) Oxford English Dictionary. (London: Oxford University Press, 1933). 
lem having only a conjectural answer." ${ }^{4)}$ Perhaps it is the frustrating puzzles inherent in a conundrum that lead to conjecture about solutions. Solutions based upon conjecture seem likely to be defective, and to continue the insoluble nature of the problem.

"Conundrum" is also used in association with an intellectual game, as in a puzzle that ends in a pun. ${ }^{5)}$ This suggests a problem that lends itself to contemplation more than to action. In dealing with conundrums, analysts may not get to the point where they agree about what should be done, or what can be done.

\section{Conundrums and Other Kinds of Problems}

It is helpful to distinguish conundrums from other kinds of problem. A simple problem has one solution, like a problem of arithmetic. In government, such a problem is presented by a client with certain characteristics, which can be matched with classifications recorded in a program manual, with the result that the client is shown to be entitled to a fixed and unambiguous financial grant or program of services.

A stubborn problem lends itself to solution, albeit slowly, and in bits. Chipping away or piecemeal solution is the strategy suitable for a stubborn problem. Disease or adult illiteracy are stubborn problems that involve identification of components that may be solved, sequentially, with an ultimate aspiration to eliminate the problem or to reduce its incidence significantly. Getting an astronaut to the moon was a classic problem of science and engineering. The task was difficult, but lent itself to being broken down into a series of manageable tasks, which were solved in sequence.

A predicament and a dilemma are problems with no attractive solutions. However, there are solutions. A predicament is a difficult situation involving "hard or unwelcome" choices. A dilemma is even stronger than a predicament, in that a dilemma involves alternatives that are equally unpleasant. ${ }^{6)}$

Political activists face dilemmas when they object strongly to all the candidates for elective office, while their commitments to good citizenship and political activism do not allow them to abstain from voting. Predicaments occur in health policy, when the resources for treating certain conditions are not adequate to the patients who could be treated. It is

4) Wester's Nerw Collegiate Dictionary, (Springfield, Mass.: G.C. Merriam Co., 1977).

5) For example, Webster's New Collegiate Dictionary, op. cit.

6) Webster's Third New Internationary, (Springfield, Mass.: G. and C. Merriam and Co., 1971). 
possible to keep some pátients alive with artificial hearts, or with transplanted hearts, kidneys, and livers. However, the number of artficial hearts available, or the number of donated organs are less than the demand. Policymakers would face the predicament if they sought to legislate general guidelines for allocating the limited number of organs. Meanwhile, physicians face agonizing choices on an individual basis when examining patients, and determining which will receive the organs that are available.

A typical political problem has several possible solutions, with a choice made through negotiations or voting. One subcategory of these problems is the predicament, whose alternative solutions are unattractive. Another subcategory is the dilemma, whose alternative solutions are equally unattractive. A common political problem is resources that are insuffcient for demands. Usually this is handled by bargaining with respect to the allocation of the available resources, or by deciding to expand the resources via borrowing or increased taxation. At the extreme, a problem of insufficient resources can become a conundrum if the pressing demands exceed by far the resources that can be obtained by all the means conceivable.

A problem that seems to have no solution. As long as no solution appears on the horizon, we have a conundrum. If conditions change and one or more solutions appear in sight or at hand, then the problem becomes one of the other categories listed above. A solution may appear as the result of reconceptualizing a conundrum to remove one or another of the components that had made a solution impossible. Or a solution may appear as a result of new discoveries in physical or social science or technology. While solutions may be offered for a conundrum, they must meet a certain minimum standard for the conundrum to become another kind of problem. The solution must reach a certain level of finiteness, or clarity. The solution need not be a "desirable" one. A dilemma or predicament would be a problem that offered solutions of finiteness and clarity, but not desirability.

Policymakers may find something they call "solutions" whenever they encounter several of the conundrums described here. Universal conundrums, such as that identified by V.O. Key, have given rise to routine solutions that one generation after the other can learn from textbooks on policymaking. For the most part, these routines ignore the insoluble components of a problem, and direct the attention of policymakers to aspects of the problem that can be solved. However, these solutions are partial and temporary. They do not prevent the same conundrum from returning, in the same form, the next time that the same policymaker (or a replacement) deals with the same issue. 
What is thought to be a conundrum may be solved by a creative policymaker. Also, a conundrum may disappear from the political agenda with changes in priorities, or as a result of changes in the conditions that produced the conundrum. ${ }^{7)}$ What makes a problem a conundrum, however, is - for the time being and foreseeable future- - the inability to find a solution.

There are cases when the same phenomenon may be labelled a stubborn problem, a predicament, a dilemma, or a conundrum by different analysts. Writers may be insufficiently sensitive to the nuances involved, or disagree in their analyses of a situation. Both "dilem$\mathrm{ma}^{\mathrm{a}}$ and "conundrum" are used as synonyms for problems that are perplexing and elude solution. Morris Janowitz, Michel Crozier, and Samuel P. Huntington have written about the dilemma of democracy, or the severe weaknesses built into polities that seem destined to offer too much by way of services, beyond their capacity to finance them or to administer them well. ${ }^{8)}$ Some of their thinking finds its way to the discussion of conundrums here.

\section{How to Recognize Conundrums}

The following traits summarize the traits of conundrums, and help in the distinction of conundrums from other kinds of problems:

- Conundrums are ambiguous. Participants and observers disagree as to how to define the problem.

-As part of their ambiguity, conundrums are multifaceted. Conundrums are made up of different components, and it is difficult to find agreement as to how the "essential" elements of the problem should be defined.

- Conundrums do not lend themselves to quantitative assessment of their components. This trait is related to their ambiguous and multifaceted qualities. Analysts may be able to measure individual economic social, or political traits said to be involved in a conundrum. However, they cannot assess the weight of each in relation to the conundrum, or project the success of programs that are offered as solutions for the conundrum.

- Conundrums are persistent. The same-or similar-problems crop up time and again, perhaps in different formulations or with different personalities playing the major roles.

7) John W. Kingdon, Agendas, Alternatives, and Public Policies (Boston: Little, Brown, 1984).

8) Morris Janowitz, Social Control of the Welfare State,(New York: Elsevier, 1976); and Michel Crozier, Samuel P. Huntington, and Joji Watanuki, The Crisis of Democracy: Report on the Governability of Democracies to the Trilateral Commission, (New York: New York University Press, 1975). 


\section{Universal and Situational Conundrums}

A pervasive conundrum that frustrates policymakers the world over can be summarized by the general statement that there are too many elements that contribute to the character of public policy in order to define with precision the impact or weight of each.

There may be no more troubling condemnation than the knowledge that issues involved in a government budget are so complex that resources cannot be allocated with any certainty as to their effects! Beyond the influences on programs that respond to the decisions of policymakers (money, the number and quality of personnel to be recruited, and program details), there are economic and social phenomena from outside the government, or even from outside the country in which the government operates. Changes in the international economy can affect a nation's well-being, for example, and change the resources available for a program, or the priority that a program enjoys in relation to other programs ${ }^{9}$

The insolubility of this conundrum affects policymakers' inability to operate according to standards of perfect rationality. Numerous scholars have documented the frustrations attendant on those who would identify their goals, list alternative means of attaining their goals, identify benefits and costs, and "take everything into consideration" in reaching policy decisions. ${ }^{101}$

However, the very universality of this conundrum has produced solutions that are accepted as conventional. Officials are taught how to allocate resources, design organizations, and implement programs without tripping on the insoluable problems inherent in the tasks. Routines exist that are good enough. Critics may harp about the imperfections, but government proceeds despite them.

Conundrums specific to situations are more pernicious, insofar as they are not so widespread as to produce evasions that come to be accepted as conventional. There is no known repertoire of tricks that Israeli policymakers can call upon to deal with their intertwined issues of inflation, an imbalance of payments, and foreign debt, plus huge resource claims for security and civilian programs. It may be in the nature of policymaking that officials try simple solutions for complex problems. ${ }^{11}$ ) Where the problems are unique, however, there is little chance of finding a simple and satisfying way of coping.

9) Henry Teune, "A Logic of Comparative Policy Analysis," in Douglas E. Ashford, ed., Comparing Public Policies: New Concepts and Methods, (Beverly Hills, 1978), pp. 43-55.

10) Charles E. Lindblom, The Policymaking Process (Englewood Cliffs, Prentice-Hall, 1978).

11) See my The Routines of Politics (New York: Van Nostrand, 1970). 


\section{What is a Serious Conundrum, What is a University Joke, and What is Some- thing Else?}

The idea of a conundrum carries within it the opportunity for serious analysis and pedantic excess. Once a conundrum is recognized as such, it may be difficult to view seriously those who persist in seeking a solution. Those features of conundrums defined as puzzle, intellectual game, or university joke are best left out of the analysis.

In this spirit, we should try to avoid paradoxes, a kind of conundrum that is rendered self-contradictory by virtue of its definition. ${ }^{12)}$ Yet some paradoxes are subtle, and invite inspection. Readers with a feel for politics and familiar with the jargon of political science recognize the paradoxes imbedded in searches for optimal solutions, or solutions that are defined in the national interest, without consideration of politics. However, such searches are made, in apparent seriousness, by reputable policymakers and commentators.

Related to the designation of a conundrum is the prior designation of what is a problem of government. ${ }^{13)}$ A problem in one jurisdiction may be only a phenomenon elsewhere. Within individual jurisdictions, phenomena can become problems with changes in perceptions and norms. Americans need no better example than the increased awareness given to the demands of blacks, other ethnic minorities, women, the handicapped, and homosexuals. If newly-perceived problems are complex and ambiguous, they become conundrums. However, problems of one day can reduce their importance and become phenomena with a change in the public's interest. There is likely to be dispute about the status of particular issues: whether they are phenomena or problems, and how high they are on the political agenda.

\section{The Importance of Wording}

The wording of a problem can make it a conundrum or something else. Conundrums of resource allocation, for example, can be phrased pragmatically in a way that budgets are enacted, financial accounts are published, and resources are directed to the problems targeted by government. How such to allocate for program " $A^{n}$ ? is a question that can be settled by negotiations or voting. A formulation like this is manageable politically, even while it evades underlying issues, such as What will be the impact of a budgetary allocation on the character of governmental programs? This is a conundrum that continues to disturb resource allocation.

12) My thanks to Stefan M. Sharkansky for pressing on me the significance of paradoxes.

13) Cbarles W. Anderson, "The Logic of Public Problems: Evaluation in Comparative Policy Research," in Ashford, op. cit., pp. 19-41. 
Crime is another issue whose definition can make it a conundrum or something else. Generations of analysts have defined crime as a problem of criminals who could be punished into reforming their ways, or guided through treatment away from anti-social outlooks and behaviors. Perhaps it is best to define the problem of crime as victims who are harmed, and to concentrate resources on their care and compensation? ${ }^{14)}$ In this way, crime is redefined from the as-yet unsolved problem of what to do about low violators to a problem of compensation for victims. This can be solved by negotiations, or voting by members of an committee.

Traffic safety can also be defined as a conundrum or as another kind of problem. It is a conundrum if defined as problems of death and destruction that should be stopped. It may be only a technical problem--subject to experimentation-if defined as an issue of death and destruction that should be lessened. It becomes a problem subject to negotiation or voting if it is defined as an issue of compensating those who survive accidents, and the estates of those who do not survive. ${ }^{15)}$

Crime and traffic safety continue to be conundrums insofar as officials persist in seeking solutions to their insoluble components. Like other conundrums considered here, they are rendered important by the attention that is paid to them by observers and reformers.

\section{The Significance of Conundrums}

The subjective components in problem definition and policy analysis make it likely that conundrums, and not simple problems, will be the stuff of politics. Policymakers are skilled in finding ambiguity in the proposals of their antagonists.

Conundrums produce shortfalls in policy accomplishments, and frustration among those charged with policymaking. In settings where policy is bound to be disappointing, advocates of different perspectives are certain to find targets for their criticisms. Thus, conundrums provide one of the underpinnings of political conflict.

Political scientists are sensitive to many "causes" of politics: loyalties to party, friends, leaders, charismatic figures, region, city, nation, ethnic group, occupation, ideological comrades, or social class. Conundrums that are imbedded in issues of public policy assure that

14) See Herbert Jacob, The Frustration of Policy: Responses to Crime by American Cities(Boston: Little, Brown, 1984).

15) See David Dery, Problem Definition in Policy Analysis, (Lawrence: University of Kansas Press, 1984). 
some political conflicts will be clothed in intellectual disputes, and not simply be cases of one group opposing another.

Political commitments rule out certain options from the list of possible solutions for a conundrum. Also, political rivalries induce policy-makers to complicate their colleagues' tasks. They know how to conundrumize a problem that they do not wish to solve. One theme of Aaron Wildavsky's Speaking Truth to Power is to recognize the probable limitations of analysis. ${ }^{16)}$ It honors the skills of political persuasion and advocacy, as ways of dealing with problems that cannot be solved by analysis alone. At the same time, it recognizes the limits of politics in dealing with irreconcilable issues.

Conundrums are involved in circular networks of cause and effect. They assure conflict about the treatment of policy issues that are unresolvable, and the disputes generated by conundrums add to the unresolvable nature of the policy issues. Some individuals thrive on conundrums. Critics who are attracted to unresolved policy issues can make the issues even more complicated by the analyses that they build into their criticisms. At the heart of the circle are the multiple and ambiguous elements of the conundrum, which attract a variety of disputes. The character of these disputes make the problem even more complex, ambiguous, and multifaceted.

Depending one's perspective, conundrums can be advantages or disadvantages. As disadvantages, conundrums are a persistent bother. They assure frustration among poicymakers seeking to solve problems, and conflict among those responsible for policymaking. Conflict about conundrums may deepen their ambiguous and multifaceted character, and make clarity of definition even more unlikely. The insoluble nature of conundrums leads policy advocates to exaggerate their chances for success. Some exaggerations are unintentional. They are offered by policymakers who genuinely feel that they will succeed in solving what is a conundrum. Or they may be the intentional exaggerations of policymakers who know that they cannot solve the problem at issue, but feel that their policy is the best availiable, and is likely to be enacted only if they exaggerate its prospects for success.

Conundrums are advantages insofar as they serve the needs of organizations and individuals for continued employment and prestige. Persistent problems require continuing treatment. Conundrums justify the existence of organizations both within the government and in the private sector that analyze problems. Analysts have an interest in keeping conundrums alive. They find ever more complex issues embedded in them, and extend the futile 16) Published in Boston by Little, Brown in 1973. 
pursuit of clarification.

Keeping conundrums going may serve important social and political purposes. By rendering disputes ambiguous, and inhibiting decisive outcomes, conundrums keep sensitive issues below the flashpoint of bitter conflict. Appointing a committee is a hackneyed trick that is used to avoid a confrontation. If the committee also wants to avoid a decisive outcome, it can call upon another hackneyed device to keep the conundrum going, and urge further research.

\section{Conundrums, Policymaking, and Politics: What to Do?}

Conundrums abound in the lives of those who would govern. Policymakers have numerous problems that invite much discussion, gnashing of teeth, and efforts at reform, but will not go away.

Perhaps this is a trivial message. Political struggle is part of the human condition. Yet triviality is one of those things that exists in the eye of the beholder. For policy analysts schooled in the limits to rationality, it may be trivial to elaborate the universal conundrum concerned with the numerous inputs to policy, and the impossibility of determining the precise influence of each. However, Presidents Johnson and Carter, and countless budget analysts and intellectuals in the United States and elsewhere invested their boundless energies in the development and propagation of Planning-Programming-Budgeting and Zero-BasedBudgeting. These and numerous other techniques of policymaking that fill the graveyard of flashy ideas suggests that the quest for a rational technique of resource allocation is impervious to the teaching of political science and public administration. During Israel's period of high inflation that evaded solution there was little awareness of triviality among Israeli citizens who were confused by escalating prices, or among Israeli policymakers who found themselves with competing analyses and prescriptions.

\section{The Significance of Coping Is to be Satisfied with Something Less than a}

\section{Solution}

To recognize the generality of conundrums is to prepare to cope with them. The use of the term coping is significant. The term implies something less than finding solutions to problems. Terms like adaptation, managing, and dealing with appear in discussions of coping. ${ }^{17)}$

17) George V. Coelho, David A. Hamburg, and John E. Adams, eds., Coping and Adaptation, (New York: Basic Books, 1974). 
A policymaker troubled by a conundrum should be aware of many intellectual, political, and administrative tricks. Usually the descriptions of them does not recognize the insolublity of the problems at issue. Adding the concept of conundrum to this discussion may assure an appropriate ingredient of skepticism, and help the policy analyst avoid serious frustration.

Satisficing is a common ingredient in the coping strategies that may help with a conun drum. ${ }^{18)}$ This is anotherword that stresses the imperfect nature of decisions. Satisfactory decisions are "good enough," even if they are not what any of the participants really want.

\section{Coping Strategies}

It is inherent in the nature of coping strategies-or tricks-that they provide only partial, or imperfect solutions to problems that are, in their nature, insoluble. Some of the ideas outlined here may actually make some aspects of a conundrum worse, even while they offer solutions to other aspects. The ideas are not entirely separable. Fuzzy boundaries and overlaps suggest the need for creativity and subtlety, as well as numerous options in dealing with insoluble problems.

1. Redefine. Pragmatic policymakers know how to focus on the soluble aspects of insoluble problems. Budgetmakers allocate resources according to negotiations or voting, without facing the classic question of V.O. Key: On what basis shall it be decided to allocate $x$ dollars to activity $A$ instead of activity $B$ P Policymakers escape from the universal conundrum of not knowing, for sure, the implications of certain inputs to complex policies when they allocate responsibilities without probing fully the implications of their decisions. Such policymakers do not wrestle with conundrums that assert that they cannot know, for sure, the effects of a particular organizational structure, or a particular plan of implementation, amidst all the potential influences upon program results. They aspire to simpler accomplishments, like achieving something close to the policy goals that have been announced.

2. Be entrepreneurial. Entrepreneurs see opportunities where others see only problems. They have the kind of creativity that Yehezkel Dror labels "extrarational." 19) Joseph A. Schumpeter's Capitalism, Socialism, and Democracy is a common source for much writing about entrepreneurialism. He wrote that the function of the entrepreneur

is to reform or revolutionize the pattern of production by exploiting an invention or,

18) The classic reference is to Herbert Simon, Administrative Behavior (New York: Free Press, 1976).

19) Yehezkel Dror, Public Policymaking Reexamined (San Francisco: Chandler, 1968), pp. 149-53. 
more generally, an untried technological possibility for producing a new commodity or producing an old one in a new way, by opening up a new source of supply of materials or a new outlet for products, by reorganizing an industry and so on. [italics added]... (The entrepreneur) act(s) with confidence beyond the range of familiar beacons... The function... consists in getting things done. [italics added] ${ }^{20)}$

The problem with entrepreneurialism appears in the entrepreneur's departure from conventional behavior. Excessive creativity is upsetting to well-established organizations. At the extreme, it may be difficult to distinguish entrepreneurial behavior from rebellion or thievery. ${ }^{21}$

3. Be devious. Insofar as conundrums present conditions of ambiguity, they are open to exploitation. Policymakers may exaggerate or otherwise mislead their adversaries, hoping to get away with something in the fog. Deviousness appears in the behaviors of certain entrepreneurs. It is alse found in the strategies of breaking the rules and indirection, to be described below.

4. Break the rules. A problem can become a conundrum if the options for dealing with it are limited by the formal definition of acceptable behavior. This combination of pervasive formal controls, and widespread evasions creates problems as well as opportunities. One problem is how to label individual violations: as corruption, ${ }^{22)}$ or as reasonable exercises of administrative flexibility that "circumvent the snarls" of central controls?" Another problem is knowing the limits of the informal rules, and how far one can go before encountering serious trouble. There is enough ambiguity here to raise the spectre of yet another conundrum. ${ }^{24}$

5. Be indirect. ${ }^{25)}$ Indirection is another way of coping with conundrums. If an element of the conundrum is a fixed blockage in the way of certain solutions, indirection may be an appropriate coping strategy. What policymakers cannot achieve directly, they may be able to achieve indirectly. If they cannot pursue (A), they might pursue (B) in the

20) Third edition (New York: Harper, 1950), p. 132.

21) For a discussion of entrepreneurialism in Israel's public sector, see my The Political Economy of Israel (New Brunswick, N.J.: Transaction Books, forthcoming), Chapter 9.

22) See Nathenial H. Leff, "Economic Development through Bureaucratic Corruption" in Arnold J. Heidenheimer, ed., Political Corruption: Readings in Comparative Analysis (New York: Holt, Rinehart and Winston, 1970), pp. 510-20.

23) James C. Scott, Comparative Political Corruption (Englewood Cliffs: Prentice-Hall, 1972), p. x.

24) See my The Political Economy of Israel, Chapter 11.

25) Thanks are due to Aaron Wildavsky for encouraging the author to develop the label and the concept, 
hope that it will lead to something that approximates (A). Indirection is more subtle than actually breaking the formal rules. It operates by evasion or avoidance rather than a headon confrontation with a prohibition against certain actions. However, there are problems with indirection. It may be difficult to know what is the ultimate policy goal (A) and what is the nominal policy goal (B). When policymakers proceed by indirection they may intend to confuse their antagonists and perhaps observers as to their goals. At times they confuse themselves, as when some members of a policymaking group (e.g. a committee of administrators of legislators) intend (B) as the real goal, while others in the same group see (B) as a route to (A). The tale of the little boy who cried wolf is a story of indirection that went bad. The boy sought attention (A) by calling wolf (B). On the day that a wolf really appeared, his companions thought he was deceiving them again. ${ }^{26)}$

6. Reform. Reform is one of the strategies pursued by those who seek to deal with conundrums. Prominent examples appear in the numerous efforts to rationalize budgeting, such as Planning-Programming-Budgeting (PPB), and Zero-Based Budgeting (ZBB). Features of these reforms caught on among budgetmakers, even if neither of the reform packages accomplished their announced intentions of allowing budget-makers a comprehensive look at competing needs. Administrative reorganization is a fertile field, with no end of plans to alter one or another government agency, or the basic structure of government. Their common failing is an inability to convince skeptics that the proposed reorganizations will have a known influence on public services, amidst all the other factors likely to be influential.

7. Add to the information available to policymakers. This is a general strategy that typically includes investments in training programs and basic research in policy analysis, and the creation of staff institutions to aid key decision-makers. It is difficult for an intellectual to argue against a proposal for more and better information. However, such a strategy must be accompanied by the warning that more advisors will not be able to solve the basic conundrum of not knowing, for sure, which of many influences on a problematic situation is critical, and which result will follow from each proposed input. ${ }^{27)}$

8. Be redundant. The very multiplicity of tricks suggested to deal with conundrums and the overlaps apparent among them suggest the merits of redundancy. Some years ago Professor Martin Landau provided the insight into the positive features of redundancy,

26) The Political Economy of Israel, Chapter 10.

27) For an example of this proposed strategy see Yehezkel Dror, Policymaking Under Adversity (New Brunswick, N.J.: Transaction Books, 1986). 
despite the conventional association of that concept with duplication and waste. ${ }^{281}$ The appeal of redundancy is that several parallel and similar approaches to a problem may cover different aspects of a problem that are not fully recognized, as well as offering backup in the case of an unexpected weakness in any one approach.

9. Accept What Exists. Decide incrementally. There is no lack of defenders for the status quo. Often it deserves defense! What are labelled as problems may be the best way of dealing with issues that truly are difficult. Incrementalism is a well-known strategy for dealing with policy problems that begins with an acceptance of the status quo. Charles Lindblom $^{29)}$ and Aaron Wildavsky ${ }^{30)}$ argue that incremental procedures reflect the dynamics of democratic politics. Incremental budgeting allocates money to those who make the most telling arguments in negotiations, backed up with the commitments of their supporters in executive budget offices and legislative committees.

10. Try Some Homilies. Perhaps the first thing to do about conundrums is to recognize what they are, and to know that they will not go away. It is possible to accomodate oneself to conundrums. They invite policy-makers to make do despite them, or to work around them while leaving the conundrum to appear again at the next time that policy is to be made. It may be possible to cope with a conundrum via one or another of the strategies described here. It may also help to employ the well-known homilies of public administration:

1) Define policy goals clearly, and keep them simple.

2) Cultivate support groups among political office holders, clients, and people with skills in mass communication.

3) Monitor program evolution, and be prepared to respond to problems as they emerge. The responses that may be required include more money, additional personnel authorizations, changes in the legislation, or the generation of public support.

11. Use good judgement. True conundrums will probably evade efforts for solution found in each of the tricks listed above. In the final analysis, policymakers need large perspective, a great deal of sound information, sensitivity to the range of relevant values, and a personal capacity to keep all their considerations in reasonable perspective.

28) Martin Landau, "Redundancy, Rationality, and the Problem of Duplication and Overlap," $P u b$ lic Administration Revierw, 29 (July/August 1969), pp. 346-58.

29) "Decision-Making in Taxation and Expenditurc," in Public Finances: Necds, Sources and Util ization (Princeton: National Bureau of Economic Research, 1961), pp. 295-336.

30) The Politics of the Budgetary Process (Boston: Little, Brown, 1964). 


\section{Conundrums, Policy Analysis, and Adequate Performance}

Conundrums are related to issues of a government's performance and its legitimacy. A government can defend itself against critics with an adequate performance of policymaking and service-delivery. In settings that are simple and peaceful, adequate performance may provide sufficient defense for the regime and the current office holders. Even in settings that are neither simple nor peaceful, adequate performance can be important in maintaining the government's rule.

The quality of policy analysis and governmental performance is bounded by conundrums. No matter how good the elected officials and civil servants, conundrums keep policymakers from knowing exactly what they are doing, force a certain amount of conjecture into their decisions, encourage posturing and exaggeration as techniques of persuasion, and put a great burden on the personal wisdom and emotional balance of policymakers. 